\title{
Genealogical Solutions to the Problem of Critical Distance: Political Theory, Contextualism and the case of Punishment in Transitional Scenarios
}

\author{
Francesco Testini ${ }^{1}$ (D)
}

Accepted: 26 April 2021 / Published online: 10 August 2021

(C) The Author(s) 2021

\begin{abstract}
In this paper, I argue that one approach to normative political theory, namely contextualism, can benefit from a specific kind of historical inquiry, namely genealogy, because the latter provides a solution to a deep-seated problem for the former. This problem consists in a lack of critical distance and originates from the justificatory role that contextualist approaches attribute to contextual facts. I compare two approaches to genealogical reconstruction, namely the historiographical method pioneered by Foucault and the hybrid method of pragmatic genealogy as practiced by Bernard Williams, arguing that they both ensure an increase in critical distance while preserving contextualism's distinctiveness. I also show, however, that only the latter provides normative action-guidance and can thus assist the contextualist theorist in the crucial task of discerning how far certain contextual facts deserve their justificatory role. I prove this point by showing how a pragmatic genealogy of the practice of punishment can inform the contextualist's reflection about the role this practice should play in a transitional scenario, i.e. in the set of circumstances societies go through in the aftermath of large-scale violence and human rights violations.
\end{abstract}

Keywords Contextualism · Methodology · Political theory · Genealogy · Punishment · Transitional justice

\section{Introduction}

There is a methodological trade-off in normative political theory that, in broad brushstrokes, may be rendered as follows. On the one hand, the theorist can start her reflection as detached as possible from local conventions, particular institutional arrangements, established practices and, in short, the specific context. From such

Francesco Testini

francesco.testini@unimi.it

1 Department of Social and Political Sciences, University of Milan, Via Pace 10, 20122 Milan, Italy 
a distance, her theorizing will be wide in scope and hopefully grounded on some universalist foundation, retaining a strong critical potential when confronted with the social and political reality. However, these desirable traits come at a price. The standards and principles resulting from this kind of theorizing may lack a specific and clear content, so to make their application problematic, and they may prove hardly appropriate in some set of circumstances. Moreover-as conservatives tend to emphasize - the practices and institutional arrangements already in place in certain contexts may embody a form of practical wisdom that a general and abstract theorization is unsuited to capture. ${ }^{1}$

On the other hand, the theorist can start with more contextually specific details. Remaining in a closer relationship with existing practices, institutions and arrangements, she may work out theoretical standards and principles better suited to address specific situations and toward which agents in those situations can be receptive. But this choice comes at a price too. Starting closer to the social and political reality the theorist runs the risk of taking for granted certain aspects of it that, from a more detached perspective, would appear as simply prejudiced or unjust, thus sacrificing the transformative capacity of political theory for an unduly conservative stance.

In this paper, I will be concerned with theorists and approaches that make the second choice and I will try to show that there are ways to mitigate its costs. More specifically, I will focus on contextualist approaches-namely those approaches to normative political theory which hold that contextual facts are a crucial point of reference for the justification of normative judgments - and on what is arguably the most deep-seated problem they face. This problem, roughly sketched above, consists in a lack of critical distance. It originates from the justificatory role that contextualist approaches attribute to contextual facts and it may be more accurately formulated as follows: if facts about the context, like local conventions and existing practices, can determine and justify normative judgments, what ensures that these judgments are not unduly biased by whatever state of affairs happens to obtain in the relevant context?

It is usually thought that this problem cannot be solved while remaining faithful to contextualism's methodological premises. I shall argue instead that there are two ways of solving this problem without endangering contextualism's distinctiveness. These two solutions consist in the application to the context of two different genealogical methods. The first solution, related to the purely historiographical method pioneered by Foucault and endorsed by authors working in the critical theory tradition broadly construed, consists in problematizing the relevant contextual facts, i.e. in providing a new perspective from which their contingent configuration and worrisome aspects can emerge. The second solution is related to the hybrid method of pragmatic genealogy, as practiced by Bernard Williams and prefigured by Edward Craig. This method combines idealization and historical reconstruction, delivering a functional interpretation of contextual facts in the light of which it is possible to ascertain whether and how the specific configuration of such facts is responsive to normatively relevant needs.

\footnotetext{
${ }^{1}$ I owe special thanks to David Owen, Matthieu Queloz, Ugur Bulgan, Stefano Sammarco and to the editors and reviewers of Res Publica for their comments on earlier drafts of this paper.
} 
Bringing about an increase in critical distance while maintaining contextualism's distinctiveness, both these methods satisfy two important desiderata, but this does not mean that they are equally useful. Indeed, I will show that these two methods fare differently when comparatively assessed in light of one more desideratum, namely normative action-guidance. Pragmatic genealogy, as I shall argue, is the only one capable of providing this guidance and thus of assisting the contextualist theorist in the crucial task of discerning how far certain contextual facts deserve a justificatory role.

Supporting my claims requires fulfilling several tasks, which I tackle as follows. First, obtaining a grasp of what contextualism amounts to and a sound formulation of the problem of critical distance. Second, establishing the list of desiderata serving as criteria for ranking possible solutions and comparing the approaches to genealogical inquiry available in their light. Third, testing the most promising one, namely pragmatic genealogy, against a real case. The test case I will employ concerns the role of punishment in transitional contexts, i.e. the sort of socio-political scenarios obtaining during the recovery of a political community from the outbreak of intergroup violence, oppression and human rights violations on a large scale. I show that approaching the practice of punishment through pragmatic genealogy in this context offers a corrective to the lack of critical distance and normative action guidance that several contextualist approaches (like Walzer's, Miller's and Sangiovanni's) would display in such a case.

\section{Contextualism and the Problem of Critical Distance}

Contextualism is probably best defined as 'a family of views holding that factual claims about the context of a case are part of the justification of normative political judgments about this case' (Lægaard 2019, p. 954). This definition applies, in an interesting variety of ways, to authors as diverse as Michael Walzer (1993), John Rawls (1993), David Miller (2001), Joseph Carens (2000), Andrea Sangiovanni (2008) and many others. The definition constitutes a good entry point in that it is informative (it delimits the domain in which context is relevant to justification), inclusive (it wisely leaves underdetermined how context is defined and how it specifically affects justification) and because it suffices to realize that contextualism is exposed to a serious problem. Since contextualism takes contextual facts as crucial features for the justification of normative judgments, concerns about the normative standing of these facts may legitimately arise, putting the value of those judgments into question. Indeed, contextual facts (like local conventions, existing practices and institutions or established relationships between individuals and groups) may reflect unjust or contingent arrangements. Therefore, relying on these facts for the crucial task of justification may transfer their injustice or arbitrariness to normative judgments, thus limiting the ambition and the transformative power of normative theorizing. In other words, the proximity between theory and practice in contextualist theorizing exposes the approach to the risk of being unduly conservative, in the sense of being biased toward the status quo, and thus to the charge of lacking critical 
distance (Buckley 2012; Modood and Thompson 2018; Lægaard 2019). We can call this 'the problem of critical distance' or, for the sake of brevity, the CDP.

There are several ways in which contextual facts can bear upon normative justification. Distinguishing between them allows one both to tell different varieties of contextualism apart and to realize that they are not equally exposed to the CDP. In what follows I shall focus on the variety which is arguably the most exposed, namely theoretical contextualism, which comprises approaches in which context determines the scope and content of normative principles and, a fortiori, the justification of judgments (at least as far as judgments are plausibly understood as applications of principles to specific cases). ${ }^{2}$ A typical example of this approach is at play in Walzer's Spheres of Justice (1983), where context is defined in terms of the social meanings that a given community attributes to specific goods. Walzer derives the content of the principles according to which goods are to be distributed from an interpretation of their social meanings, delimiting the scope of such principles to the society sharing those meanings, and this way of proceeding exemplifies theoretical contextualism's high degree of exposure to the CDP. After all, social meanings are a matter of shared understanding and they may be the outcome of a transitory (and perhaps unjust) social consensus. Moreover, they do not merely influence the application of principles, but also determine their content, thus allowing only for immanent forms of social criticism whose standards and scope remain limited and contestable. Indeed, a theory deriving distributive principles from the shared meanings of some goods, like Walzer's, can certainly condemn actual distributions failing to respect those principles, but it seems poorly equipped to challenge the meanings from which its principles are derived. ${ }^{3}$

The terms in which context is defined in the literature display as many variations as the ways in which context and justification are related. Authors defined contexts in terms of social meanings (Walzer 1983), modes of association and relationships (Miller 2001), institutional arrangements (Carens 2000) and in many other ways. I shall follow Modood and Thompson in conceiving these sets of contextual facts as picking up specific aspects of existing 'normative practices', i.e. networks of norms strongly associated with particular patterns of human behavior (2018, pp. 344-345). The reason for this choice is that social meanings, modes of associations and institutions are usually intertwined with one another to the point that one can hardly obtain

\footnotetext{
${ }^{2}$ I am here relying on Lægaard's (2019) taxonomy, that identifies two more variants of contextualism. Applicatory contextualism, i.e. the view that context co-determines the implications of general principles for particular cases, is virtually immune to the CDP because it is hard to fathom how political theory could ever tackle real-world issues without being contextualist in this way. Indeed, most if not all political theorists are contextualists in this sense. Methodological contextualism, i.e. the view that employs several contexts as a resource against which general principles are tested, revised, and justified, if not immune, is certainly quite well equipped to deal with the CDP. The reason is that this process of testing and revision can be repeated employing different contexts as benchmarks, thus minimizing the influence of any given context to the minimum in pretty much the same way as reflective equilibrium does with considered judgments. On the relationship between contextualism and reflective equilibrium, see Carens (2004).

${ }^{3}$ By immanent criticism, I mean forms of criticism appealing to criteria and standards that are internal to the practice, the institution or (more generally) the context under critical scrutiny. For a defense of immanent criticism, see Sabia (2010); for a defence of Walzer's version of it, see Solinas (2019).
} 
without the other being in place. The specific meanings attributed to goods such as healthcare and education, for instance, are usually accompanied by a corresponding view of the relationships in which these goods are exchanged, produced and allocated. Certain societies see these goods as commodities and the undergirding relationship as between providers and customers, whereas other societies see these goods in different ways and thus attach to them very different standards, expectations and social norms. Moreover, certain relationships are possible only under specific institutional frameworks and are themselves institutional (corporations, for instance, are networks of instrumental relations but also, and crucially, institutions that produce and contribute to attributing meanings to goods). In light of this degree of interrelation, I believe it is safe to maintain, as Modood and Thompson do, that most of the differences between the ways in which contexts have been defined are best understood as different perspectives on the same underlying object, namely practices. $^{4}$

\section{The Problem of Critical Distance and Three Desiderata Concerning its Solution}

Focusing on practices allows us to grasp the CDP in its most general terms and to introduce a promising hypothesis about its solution. As James Tully remarked, 'freeing ourselves from [...] the practices in which we think and act is difficult because participation tends to render their shared patterns of thought and reflection [...] prereflective and habitual' (2008, p. 32). This means that practices tend by inertia to become entrenched and apparently necessary for those who live by them, giving rise to the very problem we are here concerned with. However, practices are not simply there for us to accept. They are human products that originated end evolved in certain ways, and knowing the processes through which they emerged-as Tully suggests - may 'provide the means to criticise and evaluate [them]' (2008, p. 34). This remark about the critical potential of information about practices' origin and evolution is the hypothesis I intend to examine in the remainder. In testing this hypothesis, I shall focus on the critical role of the type of historical inquiry specifically

\footnotetext{
4 I will use the term 'practice' rather than the term 'normative practice', employed by Modood and Thompson, because I think that the very concept of practice is, in itself, already suffused with normativity. Indeed, if the concept of practice is supposed to capture some regularity or pattern of behavior-as it is - then there must be some normative element at work, implicit and undefined as it might be, for this regularity or pattern to obtain. The very concept of 'norm', after all, refers both to something usual and standard as well as to a rule, a principle or other action-guiding elements. Following Sangiovanni (2016), I rely on Southwood's account (Southwood 2011) and identify such a normative element in the pro-attitudes of participants to the practice toward the relevant behavior that the practice describes, leaving open the question of where these pro-attitudes come from and where they find expression-a position to which explicit rules, implicit norms, values, customs, conventions and the like are equally good candidates. In this view, institutions amount to a formalized and regimented type of practices and Sangiovanni's practice-dependent approach, like other versions of contextualism, emerges as concerned with a specific aspect of practices, namely their points and purposes.
} 
concerned with the diachronic reconstruction of the formation processes through which practices emerged, namely genealogy. ${ }^{5}$

This hypothesis is likely to sound counterintuitive because it conflicts with a piece of philosophical common sense, i.e. that one should not-on pain of committing the genetic fallacy - draw inferences from what Reichenbach called 'the context of discovery' (the space of causes in which beliefs and practices take form) to 'the context of justification' (the space of reason where their merits and flaws can be properly assessed) (1961, pp. 6-7). Such inferences are typically mistaken because, even assuming that a given practice originated as, say, a form of oppression, it does not follow that we thus have a reason to reject it. From a critical and evaluative perspective, what matters is how the practice fares now with respect to relevant standards, which are independent of the causes that brought the practice into being.

However, a deeper examination of the issue suggests resisting the siren voice of common sense. Indeed, even leaving aside the fact that inferences from the context of discovery to the context of justification are sometimes legitimate-as far as the two are properly linked ${ }^{6}$ - there are at least two general strategies to avoid the genetic fallacy and to make historical information critically relevant. These strategies respectively characterize two different methods of genealogical reconstruction. The first one is what I shall call the 'problematizing' strategy and it characterizes the purely historiographical version of the method pioneered by Foucault and defended, among others, by Tully himself. The second strategy is functionalist and it characterizes the pragmatic, hybrid version of the genealogical method associated with Bernard Williams.

In the pages to follow, I will show that both these methods represent possible solutions to the CDP in that they both increase the critical distance between theory and practices when applied in a contextualist framework. However, it does not follow that the two methods provide equivalent solutions. Indeed, as I shall claim, the two methods do not contribute to the same extent to the satisfaction of the relevant desiderata for an appealing contextualist political theory. Drawing on Lægaard, I take these desiderata to be (1) critical distance, (2) normative action-guidance and (3) distinctiveness (2016, p. 17). When applied to prospect solutions to the CDP, these desiderata can be formulated as follows:

1. Critical distance: First and most obviously, a solution to the CDP ought to solve the problem, i.e. it should lead to a theory whose principles do not simply reflect the dominant conceptions of, or the existing norms at work in, any given practice. The theory should rather provide a detached and autonomous perspective on the

\footnotetext{
${ }^{5}$ For a recent review of genealogy's possible contributions to political theory see Prinz and Raekstad 2020. See also Rossi 2019.

6 Pashaman (1970) Crouch (1993) and Klement (2002), for instance, agree that there are various ways in which the context of discovery and the context of justification can be non-fallaciously linked. One obvious example is that of genetically justified items, like democratic deliberations, whose normative status depend on the way in which they came about (Queloz 2018, pp. 6-7). A second example is Nozick's theory of just acquisition (1974, pp. ch. 7, section I), that derives the justice of a distribution at any given time from the justice of the various intercourses which led to it.
} 
practice and its norms, from which problematic aspects can emerge and assumptions can be questioned.

2. Action-guidance: Second, the solution should lead to a theory that does not only highlight problematic aspects of a practice but offers normative resources to address them. In other words, rather than simply spotting internal contradictions between a given norm and some feature of the practice, an appealing contextualist theory should provide reasons prescribing how these contradictions should be resolved and what agents should do when they arise.

3. Distinctiveness: Finally, the solution should not require a withdrawal from the methodological commitments identifying contextualism as a distinctive approach. This means that normative judgments ought to remain justified in virtue of contextual facts and, in the specific case of theoretical contextualism, the same holds for principles. In other words, a solution to the CDP is certainly desirable but, if such a solution requires infringing these commitments, it would not count as desirable from a contextualist perspective because it would prescribe moving-somehow and to some extent-beyond contextualism itself (or to abandon it altogether). ${ }^{7}$

The challenge posed by the CDP is particularly daunting because most candidate solutions entail a drawback concerning either the second desiderata, the third or both. Consider, as an instance, the following option. One may expand the conception of the context (say, from one practice to a set of practices), so to have a plurality of principles and norms whose possible tensions may ground critical judgments unavailable in the narrower context. Such a strategy, for someone like Walzer, would require looking holistically at various social meanings in order to spot inconsistencies either between distributive principles in different 'spheres of justice' (e.g. by showing that goods with similar meanings are wrongfully distributed differently or vice versa) or between specific principles and some more fundamental normative commitments of a given political community (assuming these commitments exist and can be retrieved). ${ }^{8}$ However, this strategy is unlikely to secure the fulfillments of the desiderata. Besides doing little to prevent the CDP from re-emerging-once again, why should we accept the norms at play in the wider context?-it grants neither action-guidance nor distinctiveness. As for the former, one may claim that such a strategy retains the same normative flaws it was supposed to correct because it

\footnotetext{
7 It is worth noticing that, among contextualists, the most common way of countervailing the CDP is to affirm some form of minimal moral universalism. For instance, Walzer (1994) qualifies his approach by distinguishing between thick and thin morality, i.e. by positing a minimal but universal normative threshold of moral decency under which contextual norms are to be rejected and through which they can be criticized. Sangiovanni (2008, p. 163) makes a similar move to criticize practices based on unmediated coercion, like slavery (see also Miller 2013, p. 69). This is certainly not the place to assess the tenability of this minimal universalism, but it is worth pointing out that its success in solving the CDP depends on a partial withdrawal from the methodological assumptions identifying theoretical contextualism.

8 In Spheres of Justice, in which he frequently insists on the pluralism of distributive criteria and against the dominance of any specific goods or principle, Walzer is skeptical about the idea that there may be a set of fundamental normative commitments in any political community. However, this skepticism is not entailed by his methodology - certain political communities might have this sort of fundamental commitments.
} 
simply identifies contradictions between existing norms, without thereby offering reasons as to how these contradictions should be resolved. As for the latter, the fact that CDP can recurringly emerge at any further enlargement of the context would push the contextualist theorist pursuing this widening strategy into the universalist's corner, i.e. toward such a broad conception of context that 'many proclaimed contextualists will not recognize this as a genuine form of contextualism at all' (Lægaard 2016, p. 18).

What is promising about the idea of employing genealogy critically is that, if such an idea is viable, there could be a solution to the CDP that does not involve any significant costs in terms of distinctiveness. Indeed, employing historical data about the origin and evolution of a practice does not require the theorist to move beyond the relevant context, but only to deepen her understanding of it, introducing 'more nuances or levels to [its] interpretation' (Lægaard 2016, p. 18). However, since there are two genealogical methods available, it is now time to assess how they fare with respect to the other two desiderata just mentioned, namely critical distance and action-guidance.

\section{Historiographical Genealogy}

The first and most established approach to genealogy is typically associated with Foucault and counts among its defenders Quentin Skinner (1998), Raymond Guess (2001), David Owen (2002), Wendy Brown (2001), Colin Koopman (2013), James Tully (2008) and, more recently, Amia Srinivasan (2019). Beyond their differences, all these authors share a common commitment to the empirical nature of the enterprise (in the sense that they take genealogy chiefly as historiographical) and a common strategy to avoid the genetic fallacy. This strategy consists in avoiding any inference from the context of discovery to the context of justification by limiting genealogy's contribution to a perspectival kind of work. More precisely, they employ information from the former to reframe and cast a new light on practices under assessment in the latter. By illuminating the role of power, accidents and other contingent factors that contributed to shaping our practices, genealogy is conceived by these authors as a way of problematizing and denaturalizing these practices, as a way of freeing us from certain frameworks in which our understanding of them is held 'captive' (Owen 2002), ${ }^{9}$ as a way to 'develop the perspectival ability to consider different possible ways of governing' (Tully 2008, p. 17) and thus to remake 'our world anew' (Srinivasan 2019, p. 144).

In this view, genealogy is not inherently critical, because it is not constitutive of what we typically understand as the activity of critique, i.e. the evaluation of a certain object through normative reasons. ${ }^{10}$ However, genealogy so conceived supports

\footnotetext{
9 As an anonymous reviewer correctly pointed out, Owen takes the idea of 'captivity' from Wittgenstein (1986, Section 115 , p. 48).

${ }^{10}$ Critique is often conceived as a negative activity, but it need not be. Art critics, for example, are not simply expected to argue about what they dislike, but also about what they like and why. It is also worth
} 
such activity by increasing the distance between the practice and the reflective agent appraising it, inducing the latter to question the configuration of the former and the assumptions on which it rests. This capacity, of course, may be hardly specific to genealogy. ${ }^{11}$ Nonetheless, it seems safe to maintain that Foucauldian genealogy, in this capacity, may work as a corrective for the lack of critical distance affecting theoretical contextualism.

But what about the remaining desideratum, namely normative action-guidance? The authors mentioned above maintain that genealogy is not in the normative business and, therefore, that it is neither suited nor supposed to provide reasons as to what should be done about a given practice. Genealogy, in this view, is a preparatory but not a constitutive component of judgment. It can provide the theorist with the sort of intellectual freedom required for an unbiased evaluation, but it does not give any guidance as to how this freedom should be employed. Most importantly, on this view genealogy cannot give this sort of guidance because it is precisely due to this reticence that the genetic fallacy is avoided. The normative action guidance desideratum, therefore, remains unsatisfied. ${ }^{12}$

\section{Pragmatic Genealogy}

To satisfy this desideratum, we must look at an alternative approach to genealogical reconstruction, namely pragmatic genealogy. Recently systematized by Matthieu Queloz (2021, 2020a, b), it runs through the work of Edward Craig (1990), Bernard Williams (2002) and Miranda Fricker (2007). Since a comprehensive characterization of this approach is beyond the scope of this paper, I want to

\section{Footnote 10 (Continued)}

noticing that this conception of critique as reasoned appraisal is not separated from the notion of actionguidance. On the contrary, it presupposes it, because the activity of providing reason for or against an object of criticism presupposes the existence of some standards against which the object of criticism is measured and in respect to which certain actions are justified. For instance, if a critic has a positive judgment of a movie, the reasons grounding her judgment are action-guiding in the sense that they can recommend and justify actions such as actually going to see the movie. In the same vein, the reasons featuring in the criticism of a policy can justify actions such as voting against it, amend it and so on. On the other hand, the notion of critical distance does not presuppose the notion of action-guidance, which is indeed treated separately here.

11 Contingency-awareness may be nurtured as well by attending to non-diachronic historical reconstructions, to ethnographic studies, to the conflicting interpretations of the same practice in the relevant society (Hills, 2020) and perhaps even to works of fiction.

12 Other scholars have recently proposed a different view, arguing for the genuine normative character of Foucauldian genealogy (see for instance Tiisala 2017, Mascaretti 2019 and Lorenzini 2020). Most of the contributions in this direction are presented as exegetical perspectives and I will not try to intervene in this interpretative debate here. However, I want to point out that these interpretations, from a theoretical point of view, are not in contrast with my point about Foucauldian genealogy's lack of action-guidance. The reason is that the claims of these scholars about normativity often concern the normative interests supporting a genealogical endeavor, not genealogy's capacity of providing action-guiding norms or criteria. They all argue that genealogy's unsettling effect depends on the method's implicit commitment to freedom but none of them advance any substantial claim to the effect that genealogy offers indications concerning how freedom (either conceived as self-government, as non-domination or as self-transformation) should be used. 
focus on two crucial features that distinguish it from its Foucaultian alternative, namely (1) the functionalist strategy through which it avoids the genetic fallacy and (2) its hybrid way of proceeding.

As for (1), pragmatic genealogy does not limit its contribution to a problematizing or denaturalizing activity. Rather, it aims at establishing a direct link between the context of discovery and the context of justification through the notion of function. The basic idea is that information about the origins and development of a normative practice does not necessarily testify for its contingent and limited nature. On the contrary, in certain cases that information can provide important insights on its functional relationship with important needs of participants, in the light of which it is then possible to evaluate the practice itself. As for (2), and in contrast with the purely empirical and documentary character of Foucauldian genealogy, pragmatic genealogy is a hybrid method: it combines historical materials and philosophical idealization in the following way. It starts by building a model-a simplified situation in which cultural factors and other specificities are bracketed-to ascertain whether there are any basic needs, i.e. practical necessities that every human society is likely to face, that a prototypical version of the practice under consideration (call it the target practice) may help to meet. As a second step, the model is then de-idealized by factoring in more socio-historically local needs and pressures that, relying on history and empirical knowledge, we know have played a role in shaping the practice in its current form. Proceeding in this way, namely by tailoring the model closer to the target practice as one proceeds, it is possible to account for the practice's emergence in terms of both the basic and the more contingent needs it conceivably emerged to serve.

This is admittedly a very compressed illustration, so let me unpack it through an example. In Truth and Truthfulness, where he offers his genealogical account of truthfulness, Williams attempts to grasp the basic point of this virtue starting from 'a small society of human beings, sharing a common language, with no elaborate technology and no form of writing' (2002, p. 41). Starting from such a simplified model allows him to formulate the elementary practical dynamics that could bring to the emergence of some prototypical version of truthfulness. These dynamics unfold roughly as follows. First, the individuals in the state of nature need reliable information about their environment. Their very survival and well-being depend on the knowledge they have about the dangers and the opportunities characterizing their surroundings. Secondly, the members of this society need more information than they can acquire individually. Different individuals find themselves in different places at different times and this reciprocal positional advantage gives them exclusive access to relevant pieces of information that others lack. Therefore, they also need a way to divide the epistemic labor and to pool reliable information. This requires encouraging individuals to contribute to the pool with sincere and accurate information and a reliable way to do so is by cultivating the corresponding dispositions to share true beliefs (sincerity) and to be careful in acquiring true beliefs (accuracy). For Williams, the virtue of truthfulness consists precisely in these two dispositions. 
Now, what is the point of such a state of nature fiction? Williams emphasizes that the state of nature 'is not the Pleistocene' (Williams 2002, p. 30), meaning that it is not an attempt to gain insights into our hominid past. Following Queloz, I believe that the state of nature is indeed best understood as a heuristic idealization: as a model certainly involving abstractions and distortions, but whose abstractions and distortions allow us to isolate instrumental dependences between a prototypical version of the target practice and certain basic human needs. ${ }^{13}$ On this view, the state of nature model serves to draft a hypothesis about the original and generic point of the target practice by showing how, already at a high level of abstraction, the interplay between certain needs generates a problem to which a prototypical version of the target practice provides a salient solution (Queloz, 2020b, p. 691).

To be sure, the state of nature model cannot take our understanding of the target practice very far, because contingent and specific historical factors intervened in its formation. For Williams, a thorough understanding of specific target practices indeed requires insights from real history and the second half of Truth and Truthfulness is devoted to their collection. For instance, in the chapter about a culturally specific form of truthfulness, namely historiographical accuracy, he shows that the remote past has not always been a subject of truthful discourse. The Greeks had a mythological conception of it well up to the fifth century and it is only since Thucydides that the idea of there being something true and accurate to say about the past got some hold in the West. Such an idea was made possible by several contingent factors, among which the invention of writing played a crucial role (2002, pp. 161-170), and it is due to this idea that the need for reliable information extended from the surrounding environment to distant times. In contemporary liberal societies, Williams argues, the need for reliable information about the past is even more pressing because liberalism rests - among other things - on the awareness of past atrocities and on the distrust toward legitimating myths (2002, pp. 255-256).

One may contend that such details provide little more than some color to the genealogy. But this is not the case. Rather, Williams's turn to real history and cultural specificities appears as a way to de-idealize the model and to account for the target practice in a non-reductive way, i.e. by factoring in the former the contingent practical pressures and the more local needs that might help to explain the particular configuration of the latter. This de-idealizing operation does not require pragmatic genealogy to turn into proper historiography by providing a step-by-step causal account of the target practice's emergence, but it certainly requires some degree of collaboration between philosophy and history. As Queloz puts it, with this second step pragmatic genealogy becomes 'a receptacle for the insights of more orthodox historiography' and serves to 'extricate from history the main practical pressures that have shaped our practices and that are crucial for understanding their retention, elaboration and differentiation into the forms they now have' (Queloz 2020b, p. 692).

\footnotetext{
13 The analogy is with models in the natural sciences, whose contribution to the understanding of phenomena precisely depends on their distorting and abstracting character. For an overview of how the contribution of models to understanding has been conceived, see Weisberg (2013).
} 
Let me now turn back to the genetic fallacy issue. How is the method supposed to contribute to the evaluation of current practices? Pragmatic genealogy offers a twofold benchmark against which the practice can be evaluated.

1. On the one hand, the practice can be evaluated with respect to how it fulfills its function(s). Since ascriptions of functionality are always relative to specific circumstances and since pragmatic genealogy makes these ascriptions primarily in relation to a simplified model, this kind of evaluation depends on the relationship between the current set of circumstances and the ones represented in the model:

a. If the two sets of circumstances are similar enough, i.e. if the target practice maintains an instrumental link to the needs it conceivably arose to serve according to the model, then the practice can be considered as continuously functional or, in other terms, as still a pointful response to certain needs (Smyth 2017, p. 1137; Queloz 2020a, p. 2015). If this continuity clause is respected, the practice is vindicated. ${ }^{14}$

b. If the relationship between the two sets of circumstances is such as to sever the functional link (for instance, because the practice simply ceased to be functional with respect to the needs in response to which it may have emerged) the practice results, to that extent, contingent. This might be a destabilizing outcome, but not necessarily so. It will prove destabilizing for the practice only as far as participants are used to thinking of it as natural or necessary in some sense (see Queloz 2020a, p. 2013).

c. If the relationship between the two sets of circumstances is such as to make the practice counterproductive to the need it was and still is supposed to serve (or if it overreaches itself, extending beyond the circumstances that make it functional), the practice can be regarded as dysfunctional and thus either worth reforming or worth rejecting. To that extent, the practice is subverted (see Queloz 2020a, pp. 2011-2012).

2. On the other hand, pragmatic genealogy also puts the practice's functions up for evaluation.

a. If the needs the practice is responsive to are ones we can recognize as important and worth fulfilling, we will have a reason to uphold the practice fulfilling them. This will be the case as far as basic needs (like the need for reliable information about the environment) and uncontroversial local needs (like liberalism's need for truthful history) are concerned.

b. If this is not the case, we will have a reason to either abandon it or reform it. This might be the case if we do not share the more local needs to which the

${ }^{14}$ For a genealogical vindication of liberalism, see Testini 2020. 
practice is responsive to or if these needs are themselves problematic (like the needs of powerful minorities, masked by the ideological terms in which certain practices are couched) (Queloz and Cueni 2020).

In light of this scheme and its reliance on needs, a few words about my use of the concept are in order. My conception of basic needs mirrors what I believe is the soundest one available, namely Wiggins's, according to which ' $y$ 's need for $x$ is basic only if what excludes futures in which $y$ remain unharmed despite his not having $x$ are laws of nature, unalterable and invariable environmental facts, or facts about human constitutions' (2002, p. 15). This definition includes first-order needs like eating, sleeping and other needs based on human physiology, but it also includes second-order needs, i.e. needs arising from the relations between individuals' first-order needs (Queloz 2010a, pp. 2018-2019). For instance, the need to gather reliable information about the environment (to which Williams's genealogy tracked down the virtues of truthfulness) falls in this category. I take these basic needs to be uncontroversial because I fail to see how someone may deny that human beings would be harmed if deprived of the capacity to gather reliable information about their environment. Therefore, I also take them as relevant in the context of functional evaluation.

Local needs, on the other hand, are more controversial. Local needs, in my view, are needs that are relative to specific socio-historical contexts and that some individuals, outside of those contexts, may not recognise as such (i.e. as needs). However, I do not wish to deny that some local needs might be problematic even from within the relevant socio-historical predicament. Indeed, as I claimed above, it is precisely on this possibility that an important aspect of a practice's evaluation rests. Whether these are real needs, needs that deserve reflective endorsement or needs that may be addressed in ways that do not involve the practice to which they are related are all legitimate and welcomed questions, but questions that pragmatic genealogy alone cannot address. The normative resources to answer them are to be provided by the theorist. $^{15}$

This account should suffice to show why pragmatic genealogy is certainly a more ambitious and yet a more promising option than its purely historiographical counterpart, at least for the sake of theoretical contextualism. Indeed, examining a practice with the tools of pragmatic genealogy seems a good way to satisfy the critical distance desideratum because far from taking a practice for granted the method allows its functional evaluation. Most importantly, however, the method seems to satisfy the action-guidance desideratum as well. Rather than simply performing a perspectival work and preparing the theorist for judgment, the method's reliance on needs offers a pragmatic background against which it is possible to evaluate a practice's

\footnotetext{
15 In political theory and moral philosophy, some authors working on needs advocated for a reorientation of moral and political discourse around this notion (Reader 2007, Hamilton 2003). But the fact that pragmatic genealogy relies on it does not mean that the method presupposes or entails this view. For a thorough discussion about local needs and their role in functional evaluation, see Queloz and Cueni 2020, pp. 26-32.
} 
merits, thus orienting judgment and offering reasons for action. Now is time to see whether the method delivers on its promises.

\section{The Test Case: The Role of Punishment in Transitional Contexts}

The methodological guidelines I have sketched so far are admittedly quite abstract. To show the relevance of pragmatic genealogy for theoretical contextualism, let me thus examine what difference the method makes in dealing with a case in which, as I shall argue, different forms of theoretical contextualism are likely to give problematic answers. The case I will briefly discuss concerns the role of punishment in transitional contexts, i.e. in the sort of socio-political scenarios following the outbreak of inter-group violence, oppression and human rights violations on a large scale (Teitel, 2000). I will try to understand what kind of principles of punishment three major versions of theoretical contextualism would provide and then illustrate how a pragmatic genealogy of punishment might affect this answer. My discussion will inevitably be tentative and unrefined since both punishment and transitional justice are the subjects of extensive debates. At any rate, my aim in what follows is not to make a salient contribution to these debates, nor to flesh out a comprehensive genealogical account of the practice of punishment (which would deserve a book-long treatment), but rather to illustrate what difference does it make, from the standpoint of theoretical contextualism, to approach the interpretation of practices through pragmatic genealogy.

The transitional scenario is a valuable 'test case' to bring this out. The notion of 'test case' is here employed in a rather technical sense, borrowed from software engineering. In this sense, a test case is a simplified set of inputs and operative conditions through which it is possible to verify a program's performances concerning specific parameters. The case of punishment in the transitional scenario performs precisely this role: the elements of the case are to some extent simplified, but they are so in order to allow a perspicuous evaluation of theoretical contextualism with respect to specific parameters. For our purposes, these parameters are critical distance and action-guidance, as previously defined. Once I have demonstrated through this test that theoretical contextualism is defective in their regard, I will be able show that (and how) pragmatic genealogy can correct these deficiencies.

Before running the test, let me say a few more words on the case at hand. It is well known that a conflictual relationship between the demands of retributive justice and the demands of peace characterizes transitional scenario. In transitional circumstances, justice and peace can raise inconsistent demands that give rise, if not to dilemmas, then at least to substantial trade-offs. Seeking just convictions for all those involved, for instance, may threaten peace if a large part of the population took part in the crimes to be addressed, running the risk of remarking the very sectarian borders along which the violence occurred (Eisikovits 2014). On the other hand, partial amnesties, truth commissions and other non-punitive tools of transitional justice seem to acquire peace at the price of justice, painfully dismissing the demands of those who have been persecuted. 
In the transitional justice debate, many scholars support the demands of peace, downplaying the role of punishment as a tool to deal with past atrocities, while advocating for restorative practices, truth commissions and so forth. Even those who are less sympathetic with the claims of peace typically concede that punishment in transitional scenarios is an issue to be handled carefully and, perhaps, selectively. Few deny that at least the most serious violations of human rights ought to be punished, yet virtually everybody agrees that the application of normal culpability standards in cases of this sort can jeopardize the transition to a peaceful and just society, for a variety of reasons. For instance, the sheer number of individuals who colluded with the past regime might be too big, some of these individuals might have knowledge and capacities essential for the state-building process to be initiated and so on (see Pfiffner 2010). For reasons that will become evident later, it is worth keeping in mind that in the longstanding debate about transitional justice this balance between justice and peace has been pursued in two different ways. During the nineties, most scholars tried to reach such a balance at the level of judgment. This means that the dominant view on the issue involved two or more conflicting principles or values, whose conflicting demands had to be balanced in light of specific circumstances. More recently, scholars like Larry May (2012) and Colleen Murphy (2017) addressed this balancing task at the level of principles, claiming that transitional justice is a distinctive kind of justice whose principles and virtues already embed a concern for peace and reconciliation. I will come back to this point.

As for the practice of punishment, there are a few details to be pointed out. From the end of WWII up to the 1970s, many Western countries had a broadly correctiverehabilitative approach to legal punishment. Starting from that decade, however, several concerns eroded the academic and political consensus supporting that approach. These concerns mostly regarded the degree of interference that a correction-oriented system subjected convicts to, the substantial discretion it granted to judicial, administrative and social workers, the disparity and indeterminacy in sentencing it allowed and, as conservatives have been eager to stress (especially in the US), its softness on crime. On the other hand, the approach now dominant - the 'justice model' of punishment, as Barbara Hudson called it (1987) — is rather minimalistic and mostly retributive: eschewing correction and rehabilitation from its declared goals, it displays a backward-looking orientation focused on the retrospective features of the situation (who caused harm? Did they mean to? Could they avoid it?) rather than the prospective ones (will punishment serve as a lesson? Are they likely to offend again?), and it places notable emphasis on the notions of proportionality and desert (both of offenders and victims). ${ }^{16}$ For the sake of the argument, I shall assume that the society facing the challenges of the transitional scenario is as fond of this justice model of punishment as many Western countries are. Let me now examine what sort

\footnotetext{
${ }^{16}$ The most influential and earliest version of this model is arguably the one provided in Von Hirsch (1976). For a more detailed picture, see Hudson (1987). For the pivotal role of victims in this model of punishment, see Prittwitz 1999, Remmtsma 1999, Fletcher 1999, Haque 2005 and Kaufman 2013. According to Maculan and Gil Gil (2020, p. 133), this focus on victims in penological discourse fostered the punitive tendencies of some international courts dealing with cases of transitional justice, especially the Inter-American Court of Human Right (on this point see also (Malarino 2012, Sanchez 2009; Seibert-Fohr 2009).
} 
of principles its members should follow when distributing punishment according to theoretical contextualism.

\section{Variants of Theoretical Contextualism and their Responses}

According to my characterization, theoretical contextualism is an approach holding that contextual facts determine the scope and content of principles. This characterization, however, is too abstract to get a grasp on how this approach would address the transitional case. Therefore, let me select three specific variants of it. One way to do so is by distinguishing between authors focusing on different aspects of practices. Three approaches stand out in the literature: Walzer's, whose focus is on social meanings; Miller's, whose focus is on relationships; and Sangiovanni's, whose focus is on the point and purpose of existing practices. As I will show, these three variants of theoretical contextualism, when tested against the transitional case, display a lack of critical distance (in the sense that they tend to define the role of punishment in the light of the dominant retributive conception of the practice) and/or a lack of actionguidance (in the sense that they lead to indeterminate results as to what role (if any) punishment should play in the transitional case).

\section{Walzer and Social Meanings}

In Walzer's case, the focus is on social meanings, i.e. the shared understandings that members of a given community have of certain goods. The principles regulating the distribution of goods are supposed to be justified by, and expressive of, the meanings that a given political community attaches to them. Of course, punishment hardly qualifies as a good for the punished, since it conceptually requires the infliction of some sort of hardship or at least the deprivation of some goods. Yet it is reasonable to assume that Walzer's scheme applies to it as well (for one thing, because the punishment of offenders might be considered a good for their victims).

Now, applying Walzer's approach to punishment in the transitional case is quite challenging. After all, since inter-group violence occurred, the society at hand may lack the degree of cultural homogeneity sufficient to reconstruct determinate meanings. They might disagree, for instance, about the kinds of acts worth punishing. Most importantly, however, there is a relevant sense in which the political community itself, presupposed by Walzer's approach, might not exist anymore so that the question about whose meanings should be taken into account lacks an obvious answer. Yet even assuming that these issues are not serious hurdles to the application of the approach, it is hard to see how Walzer's focus on social meanings could avoid endorsing the justice model of punishment. Assuming the society in the transitional scenario is similar enough to ours, the social meaning attached to punishment will have a retributive core and punishment will accordingly be distributed quite generously, according to principles whose defining features will be proportionality and responsibility. To be sure, at the level of judgment, Walzer has other tools to avoid the conventionalist tendencies of his approach (illustrated in Miller 1995), but 
the fact that such an approach has this kind of tendency as far as principles are concerned is hardly contestable.

\section{Miller and Modes of Association}

For Miller, the salient aspects of practices are not the social meanings attached to the goods they produce or distribute, but the relationships they establish between individuals. The appropriateness of normative principles, in this framework, depends on the relationships or modes of association they are supposed to regulate (2013, p. 49). For instance, principles of desert are appropriate to regulate instrumental relationships, like the one between employer and employee; principles based on needs are appropriate in the context of a solidaristic community like the family; and principles of equality are appropriate in the context of political associations, like state membership or, to put it in Miller's words, 'citizenship' (for details, see Miller 2001).

On the one hand, Miller seems more critically detached than Walzer from social and political conventions. After all, relationships are apparently formal features of the context and focusing on them allows him to eschew deference toward local meanings and to criticize these meanings when they are not in tune with such features. On the other hand, however, it is not clear how purely factual accounts of how people are related to one another can ground or trigger specific principles. As has been noticed-and as Miller himself noticed-relationships are always suffused by a variety of local norms and by ideas concerning their normative significance (Modood and Thompson 2018, p. 344; Buckley 2012), to the effect that different cultures attach different values to the same relationships (Miller 2013, p.170).

In the transitional case, this raises a problematic point concerning both the sort of relationship Miller's approach would pick up and its normative import. The victimsoffenders relation seems like an obvious choice and, given how the justice model frames this relationship, one is left to suspect that retributive principles based on desert would emerge as the appropriate ones for the allocation of punishment. If the choice falls on political membership and citizenship, thus requiring a principle of equality, it is obviously up to the theorist to decide which is the most appropriate one. But since the transitional context is specifically concerned with addressing human rights violations and crimes, a principle of equality in front of the law seems hardly avoidable and this kind of equality principle, in such a context, warrants a quite extensive resort to punishment as well. To be sure, one may focus on the relationship between the two or more groups involved in the conflict as components of one political community that somehow came apart, thus supporting either a rehabilitative take on punishment or the employment of alternative, restorative tools. But this indeterminacy cannot be resolved merely from the methodological remarks Miller provides. As these few equally plausible hypotheses illustrate, Miller's approach delivers quite undetermined results and thus fails to provide actionguidance in this context. 


\section{Sangiovanni and the Point and Purpose of Practices}

Finally, let me consider Sangiovanni's practice-dependent approach. The approach falls squarely into the category of theoretical contextualism in that, as Sangiovanni declares, 'the content, scope, and justification of a conception of justice depends on the structure and form of the practices that the conception is intended to govern' (2008, p. 138). For my purposes here, this approach is particularly interesting for two closely related reasons. First, because Sangiovanni's methodological proposal shares with pragmatic genealogy an emphasis on the functional aspect of practices, i.e. on their point and purpose. Second, because Sangiovanni's proposal embodies a synchronic approach to functional interpretation which is at odds with the diachronic one at work in pragmatic genealogy. Instead of the complex combination of idealization and de-idealization required by pragmatic genealogy, Sangiovanni's synchronic approach focuses on the 'here and now' and requires just two simple steps. First, the interpreter determines the point and purpose of the target practice relying on its structural features and external characteristics. Second, the interpreter assumes the perspective of participants to reconstruct what reasons they might have to affirm the practice's basic rules and standards. In fulfilling both these tasks, Sangiovanni argues, the interpreter ought to respect the principle of interpretative charity, thus understanding the practice as 'an integral whole, whose parts work together to realize a unique point and purpose' (2008, p. 149). With these materials in hand, 'the content, scope and justification of a conception of justice is worked out in light of both its intended role within existing institutions and the interpretation of the point and purpose of those institutions' (2008, p. 150).

This synchronic approach seems more appealing than the diachronic one I proposed, both because of its simplicity and its focus on the 'here and now'. In the face of this, one may argue that information about origins and developments are redundant in ascertaining the functionality of practices. Why bother with diachronic historical inquiries if a practice's function can be determined synchronically? I gladly concede that synchronic approaches are more straightforward and often earn their keep. Sangiovanni's method, for instance, proved to be quite efficient in dealing with highly institutionalized practices in the international sphere. Therefore, I am also willing to concede that as far as synchronic approaches to functional interpretation like Sangiovanni's practice-dependence produce clear and reliable results, there is no need to engage in the complex diachronic modeling of pragmatic genealogy.

However, many practices are quite impervious to synchronic approaches and in such cases, as I shall argue, pragmatic genealogy represents a viable and useful alternative. In social and political theory, practices that are the product of complex historical processes along which repurposings and alterations took place (to the effect that they now display a variety of functional aspects) are the most prominent examples. ${ }^{17}$ And punishment, as Nietzsche noticed, is probably the most representative

\footnotetext{
17 Other cases in which pragmatic genealogy can make a useful difference when compared to synchronic approaches are (1) practices that apparently lack a point altogether and (2) practices that seems to serve either (2a) only basic, uncontroversial and quasi-anthropological needs or (2b) only very local and contingent needs. In each of these cases, the possibility of devising a prototype of the practice afforded by
} 
instance of this kind of practice. Even at the most abstract level, punishment is indeed overladen with functions of all kinds (Nietzsche 2006 [1887], p. 54), ranging from deterrence to retribution passing through rehabilitation, incapacitation, censure and many others. Such a variety is not a problem in and for itself, since it is perfectly reasonable for a practice to have different functions or, in other terms, to be responsive to different needs at the same time. However, such a variety can, and in fact does, give rise to conflicting interpretations respectively emphasizing one or another of these functions, leaving one to wonder how to deal with this variety. ${ }^{18}$

To see how impervious a practice like punishment is to synchronic approaches, consider how the practice-dependence method would approach it. The first significant problem arises as soon as the first step is taken. With practices of this sort, sticking to the interpretative principle of charity is not only difficult but also misleading, because the principle's commitment to coherence entails the risk of projecting onto the practice a unity that it may lack. As Lægaard nicely puts it, in such cases any claim about what constitutes the unique point and purpose of a practice or institution is a political attempt to seize the 'definitorial power' over the practice (2017, p. 96). Moreover, even assuming the interpreter can get a grasp on some function of punishment as fundamental by attending to the outward features of this practice, to its implementations and its position in the general institutional framework, this interpretation is extremely likely to reflect the dominant view of the practice in a specific social and political context. In a country like the US, for instance, a brief look at courts' proceedings, judicial records, sentencing guidelines, criminal legislation and the prison system would force any sensitive interpreter to conclude that the point and purpose of punishment is (and thus should be) sheer retribution.

The second step faces at least three related hurdles. First and foremost, it is unclear who exactly counts as a participant. In the case of punishment, a narrow way of drawing the participants' circle is by encompassing just individuals with an active role, thus including only law enforcement agents such as attorneys, judges, police officials and administrators; a broader circle, enlarged to individuals with passive roles, would include at least victims and offenders too. In the case of punishment, this is far from being a trivial issue because people at different ends of the practice may have very different and conflicting ideas about the reasons to uphold it in its current configuration - or to not uphold it. Secondly, it is unclear what the interpreter is supposed to do when the reasons provided by participants conflict either with one another (the chances of which are likely to increase as the circle of participants is enlarged) or with the point and purpose identified in the first step. ${ }^{19}$ Finally, it is worth reminding ourselves that although granting a role to participants' reasons in the functional interpretation of the practice is undoubtedly a sensitive move,

\section{Footnote 17 (Continued)}

pragmatic genealogy allows the running of a reality check. In (1), it provides guidelines to ascertain whether the pointlessness of the practice is only apparent or not. In (2a) and (2b), it can assess whether there is something more generic or more local worth knowing about the practice. For a discussion of these cases, see Queloz (2020b).

18 For an overview, see Fletcher (2000, pp. 410-440), Alschuler (2003) and Kelly (2018).

19 This problem and the previous two has been pointed out in Lægaard (2017). 
certain unjust practices tend to be rationalized by participants (especially active ones) and that focusing on their reasons may thus have significant costs in terms of critical distance, resulting in rather complacent interpretations.

These considerations show that tackling punishment with the synchronic approach engendered in Sangiovanni's practice-dependence method would yield either indeterminate results or a reductionist account which is likely to reproduce the status quo, granting primacy to whatever function of punishment is prioritized in the socio-political context at hand. Moreover, the transitional scenario makes the first outcome more likely-since there might not be a stable institutional framework around the practice anymore, an appreciation of the latter's role in light of a broader whole would be hard to obtain — and the second more problematic-because the challenge posed by transitional scenarios is precisely that of designing new institutions (or, less ambitiously, rethinking and reforming existing ones).

Since-as I showed-similar conclusions hold in the case of Walzer and Miller, one can hardly avoid the conclusion that theoretical contextualism is ill-suited to deal with the transitional scenario. This approach either leads to indeterminate principles as to what role (if any) punishment should play in the transitional process (something we can take as a lack of action-guidance), or it tends to define this role simply in light of the dominant conception and configuration of the practice (something we can take, in this case, as a lack of critical distance). ${ }^{20}$

\section{Toward a Pragmatic Genealogy of Punishment}

To bring out what difference a pragmatic genealogy can make for the functional interpretation of the practice of punishment, let me take the cue from a recent contribution to the debate about its role in transitional justice. Maculan and Gil Gil (2020) recently argued in favor of a careful and limited use of punishment in transitional contexts, claiming not only that such contexts pose very specific challenges that punishment is unsuited to meet (and that can be met with other tools), but also claiming that the basic function of punishment is to promote 'the conservation of the group' and the 'social order'-goals that an extensive employment of punishment would make hard to achieve in transitional cases. The interesting point about Maculan and Gil Gil's argument, for our purposes, is the ground on which they revendicate the primacy of this pro-social function of punishment against others. Drawing on anthropological and psychological studies, they argue that our retributive impulses 'respond to the calculated reciprocity mechanism' we share with other animals and which 'acts as a preventive tool', ultimately serving to promote the conservation of the group. 'Even when the punishment does serve to satisfy the needs for reciprocity that are so firmly inherent in our system of social interrelations', they continue, 'this purpose is ultimately instrumental'. For this reason, they claim, the victims' right to satisfaction should never be placed as a purpose in itself or seen as superior to the classic preventive aims of punishment. It cannot eclipse or replace

\footnotetext{
20 The problematic character of this second possibility does not depend on the assumption that a retributive approach to punishment is the wrong answer in transitional cases (this would obviously beg the question), but on the ways in which the approaches just examined arrive at this answer.
} 
the main rationale of criminal law, that is, to protect legal interests and the social order' (2020, p. 141).

Pragmatic genealogy offers a useful framework to harness the psychological and anthropological insights to which Maculan and Gil Gil appeal to. ${ }^{21}$ It can do so by devising a model through which the structure of instrumental dependences relating the various functions of the practice, from the most basic to the more socio-historically local, become visible and perspicuous, helping us 'situate, contextualise and accounts for each of the different functions [the] practice acquired, thereby imposing a form of order' (Queloz 2020b, p. 699). By doing so, pragmatic genealogy can provide a framework for those insights and a benchmark against which the practice can be evaluated in the relevant set of circumstances. Most importantly, since pragmatic genealogy is neither committed to methodological assumptions about the functional unity of the target practices nor is particularly concerned with the reasons of its participants, it can do so while avoiding the pitfalls that a practice-dependent approach might fall into. As I anticipated, a thorough genealogical account of punishment would be well beyond the scope of this paper. Nonetheless, the circumstances of the transitional case do not require a full account to flesh out a dysfunctionality argument along the lines Maculan and Gil Gil sketched. If pragmatic genealogy can support the claim that punishment conceivably arose to serve a pro-social function, the fact that it would be detrimental to this end in transitional circumstances would constitute a robust dysfunctionality argument against the practice.

In its barest outline, a pragmatic genealogy of punishment would roughly go as follows. If we imagine a society in the kind of situation Williams envisaged, we can be sure that its members would need some way to secure pro-social behavior in its members because anti-social attitudes make it notoriously difficult to solve the sort of coordination and cooperation problems that would prevent them, as a group, to meet the challenges posed by the environment, by other groups competing for resources and so on. There is a variety of ways in which this can be achieved. Even assuming that members of this society are not all kin, as far as their number is small enough for most members to know each other and for chances of future re-encounters to be high, this society may do well enough in ensuring pro-social behavior simply through the promotion of certain codes of conduct among, and through the cultivation of certain dispositions in, its members. Under these conditions, anti-social behavior might be discouraged by the prospect of reputational damage and thus

\footnotetext{
21 There is a voluminous empirical literature on punishment, extending beyond the domain of both psychology and anthropology and well into evolutionary game theory and behavioral economics (for an overview, see Cushman 2015). As I wrote in the section outlining pragmatic genealogy's ways of proceeding, the method constitutes a form of model-building operating through distortions, abstractions and idealization. However, this does not imply that empirical insights, when available, should be discarded in outlining the model. The reason is that such insights are helpful for distorting, abstracting and idealizing in a sensible way. After all, if pragmatic genealogy is best understood a kind of abductive reasoning, i.e. as a tool to make inferences to the best explanation (Queloz 2020a, p. 2012, Klement 2002), reliable empirical insights deserve a place in any explanation aspiring to this title. It is interesting to notice that some anthropologist and law scholars concerned with the functional origins of punishment sketched general explanations as to how such a practice may have emerged resorting to abstract and paradigmatic predicaments like the ones on which pragmatic genealogy rely (see for instance Lampe 1970, 1987).
} 
social exclusion, by the close relationship between members, by the motivational pull of dispositions and internalized norms of conduct and so on.

However, no such system of socialization is likely to be efficient as the population size increases, as the affective ties among members become thinner and the opportunities for free-riding multiply. One way in which members can protect themselves from anti-social agents is for members to develop the sort of retaliatory attitudes familiar among those scholars who studied vengeance in so-called honor cultures, i.e. cultures in which honor and shame are central elements of the ethical vocabulary. Indeed, as many anthropologists and evolutionary psychologists argued, there are good reasons to think that honor and shame, together with the retaliatory attitudes they engender, fulfill a double function in societies that lack reliable institutions of norms enforcement. At the individual level, a retaliatory attitude against offenses fulfills a signaling function, showing to possible offenders that the agent is not one 'to mess with', thereby discouraging potential attackers (Nisbett and Cohen 1996). At the social level, a widespread disposition toward retaliation can constitute a diffuse and decentralized system of deterrence against anti-social agents. The more entrenched and diffused this disposition is, the more effective it is likely to be in securing this effect. Following this reasoning, we can understand the reciprocity mechanism engendered by retaliatory attitudes in pro-social terms, i.e. as an individual and social tool to secure peaceful conditions of cooperation by way of deterrence.

Punishment, as Bedau and Kelly noticed, 'is not a social institution that every conceivable society must have' (2019) and the model here outlined nicely backs up this idea. Indeed, the very notion of punishment-as opposed to the negative feedback required by the socialization of norms and the retaliatory acts which vengeance consists of-requires some sort of legitimate authority to get some conceptual grip. ${ }^{22}$ To arrive at something like it, more local pressures have to be consideredfirst and foremost, the absence of reliable tools to manage and defuse the possibly endless spirals of violence that a widespread retaliatory disposition to vengefulness may generate. ${ }^{23}$ If this crucial condition obtains and exerts its pressure, then we can imagine something like a prototypical version of the practice of punishment to arise out of the centralization of retaliation in the hands of an authority both to avoid the escalation of revenge cycles and for deterrence.

The model allows us to make two further inferences. First, we can infer that this authority will need some sort of legitimacy in the eyes of those subjected to it because an authority without authority, as it were, would hardly succeed in those two tasks. This need for legitimacy, depending on the cultural resources and the

\footnotetext{
${ }^{22}$ This is the case even outside the socio-political context. Parents may be said to punish their children, as opposed to simply impose hardship on them for educational purposes, precisely because they can claim to be legitimate authorities in the family. Similar considerations hold, for instance, in the workplace, in clubs, churches and the like. This is-admittedly-a narrower notion of punishment than the one at work in psychology, game theory and behavioral economics.

23 Since Malinowski (2018 [1926]), several studies have indeed pointed out that vengeance and feuds are not inherently unstable and uncontrollable phenomena. Byock (2003), for instance, showed how ecological and cultural factors can help accounting for the successful regimentation of feuds among and within Icelandic Viking communities. For other interesting case studies see Lorini and Masia (2015).
} 
social structure of specific societies, will be satisfied in different ways in different social contexts, but it is reasonable to assume that the legitimation will generally involve some form of regulation of the role taken up by such an authority. Secondly, and most importantly, we can infer that this authority will allocate punishment regardless of instrumental considerations about deterrence. ${ }^{24}$ Indeed, were the practice to wear its function on its sleeve, it may not be able to fulfill it, because antisocial agents could disincentivize punishment by signaling to not be scared by its implications, i.e. to not be deterred by them. And as has been pointed out, the same degree of exposure to exploitation concerns other instrumental considerations about punishment, like correction (Cushman 2015, p. 123). Taken together, these inferences point to a strong pragmatic rationale for a retributive and backward-looking configuration of punishment based on desert rather than an instrumental and forward-looking one. To that extent, these inferences lead to a prima facie vindication of the practice as envisaged in what I called, following Hudson, the 'justice' model.

In more formal terms, the argument so far might be expressed in the following way:

P1: In a prototypical group $G$, a set of needs $N_{1}-N_{\mathrm{n}}$ under root circumstances $C_{1}-C_{\mathrm{n}}$ generate a practical problem.

$\mathrm{P} 2$ : This generates a pragmatic pressure on $G$ to solve the problem: the basic need $B N$.

P3: Prototypical practice $P$ would meet the basic need $B N$ by discharging function $F$.

P4: $P$ could develop quite naturally, i.e. out of the capacities we are prepared to grant $G$ anyway, via the set of steps $S_{1}-S_{\mathrm{n}}$.

C1: Therefore, $P$ would be bound to develop in any $G$ that persists

C2: Therefore, it is rational for $G$ to engage in $P$ in order for $F$ to be discharged in $G$ (in the sense that people with these needs under these circumstances would welcome and, if they could do so, aim for engagement in $P$ with a view to the discharge of $F$ )

P5: In the actual group $\mathrm{G}^{*}$, there are close analogues to $N_{1}-N_{n}$ and $C_{1}-C_{n}$, namely $N^{*}{ }_{1}-N^{*}{ }_{n}$ and $C^{*}{ }_{1}-C^{*}{ }_{n}$.

C3 Therefore, it is also rational for $G^{*}$ to engage in $P^{*}$, the closest analogue to $P$ in $G^{*}$, in order for $F$ to be discharged

C4 Therefore, the best explanation for why we go in for $P^{*}$ is that it discharges function $F$

C5 Therefore, there is a prima facie reason for $G^{*}$ to continue $P^{*}$, and $P^{*}$ is to that extent vindicated ${ }^{25}$

\footnotetext{
${ }^{24}$ This is a claim about the configuration of the practice, i.e. about the way punishments are practically allocated, not about the way in which the practice is justified. As far as the authority's legitimacy does not simply rest on theological or mythical grounds (and sometimes, even when it does), the imposition of hardship through punishment is a kind of act with a dire need for justification and many considerations are apt to perform this role.
}

25 Adapted from Queloz 2020a, p. 2020. 
The model might be de-idealized further, factoring in more local needs and pressures. ${ }^{26}$ This would allow controling whether the circumstances under which the practice assumed more specific functional aspects are relevantly similar to the circumstances obtaining in contemporary societies. Doing so would be necessary to assess whether the justice model still represents a pointful response to the local needs we have now and to what extent, instead, it proves responsive to local needs we might find problematic. But given our illustrative purposes, our focus on the transitional scenario, and the exceptionality of the circumstances characterizing such a scenario, it is not necessary to harness Maculan and Gil Gil's insights into a genealogical dysfunctionality argument. The structure of instrumental dependences reconstructed through the model vindicates the primacy claim of the pro-social function of punishment, offering a perspicuous understanding of how retribution conceivably grew out of it. In light of this reconstruction, we are in the position to claim that under the circumstances of the transitional scenario, in which an extensive resort to punishment may threaten a peaceful and stable coexistence, a retributive approach to punishment's distribution would not only fail to satisfy the continuity clause (thus failing to fulfill what we have reasons to take as punishment's basic, pro-social function); its implementation would also be detrimental to that function, impinging on the satisfaction of the very basic need that the practice of punishment itself primarily emerged to address, namely that of ensuring social peace and the condition of cooperation. $^{27}$

Complementing the formal exposition provided above, the scheme of the argument proceeds as follows:

P6: In the actual group $G^{*}$, there are close analogues to $N_{1}-N_{\mathrm{n}}$, namely $N^{*}{ }_{1}-N^{*}{ }_{\mathrm{n}}$, but a different set of circumstances $C^{\dagger}{ }_{1}-C^{\dagger}{ }_{n}$.

P7: $C^{\dagger}{ }_{1}-C^{\dagger}{ }_{n}$ are such as that $P^{*}$ would impinge on $N^{*}{ }_{1}-N^{*}{ }_{n}$.

C6 Therefore, $P^{*}$ would be dysfunctional with respect to $N^{*}{ }_{1}-N^{*}{ }_{\mathrm{n}}$

C7 Therefore, it is irrational for $G^{*}$ to engage in $P^{*}$ in order for $F$ to be discharged

C8 Therefore, there is a prima facie reason for $G^{*}$ to refrain engaging in $P^{*}$ in $C \dagger_{1}-C \dagger_{\mathrm{n}}$ and $P^{*}$ is to that extent subverted ${ }^{28}$

\footnotetext{
${ }^{26}$ For instance, one may account for the transition from corporal punishment to a prison-based and predominantly corrective view of the practice between the late nineteenth century and the twentieth century by factoring in (among other things) the need for a stable labor force in increasingly industrialized capitalist societies—a factor highlighted, among others, by Ignatieff (1978), Melossi and Pavarini (1981) and Foucault (1977). For an account of the transition from the corrective model which has been dominant up to the 1970s to the retributive justice model still dominant today see Hudson 1987 and Garland 2001.

27 This point might be strengthened by showing that, in the current circumstances, other derivative functions of punishment either a) do not satisfy the continuity clause (thus making the practice pointless as far as that function is concerned) or b) can be fulfilled in alternative ways (thus making the practice redundant as far as that function is concerned). In the transitional case, an argument of type (a) can be made for deterrence, because once the power structure, the institutional framework and the ideological background that supported the mass violence are removed, the chances of relapsing in the same sort of violence are likely to be low. As for the expressive function of punishment, i.e. its role as a way to express a community's condemnation of certain behavior and to uphold certain norms and values, arguments of type (b) are available, because this result can be achieved without punishing.

${ }^{28}$ The exceptionality of the transitional case makes it particularly easy to substantiate P7 whereas fulfilling this task, in standard circumstances, would require more effort. This is one reason why I defined it as a test case, in the technical sense clarified above.
} 
There are two aspects worth clarifying about this line of argument. The first aspect concerns its relevance for theoretical contextualism. In my view, the argument maintains its relevance both upstream, at the level of principles, and downstream, at the level of judgments. The first level is certainly the most important for theoretical contextualism. At this level, the relevance of the argument consists in its providing a reason against granting the practice of punishment (retributively conceived) the normative status it enjoys under theoretical contextualism, namely that of justificatory reference. This may reasonably lead some theorists to abandon the approach, but this does not necessarily follow. Indeed, once we recall that theoretical contextualism holds that contextual facts determine the scope and content of principles and that, as we saw, these contextual facts are typically identified with certain aspects of existing practices, an alternative becomes available. This alternative consists in registering the dysfunctionality argument I proposed and changing the conception of the relevant context accordingly to include a wider set of facts as justificatory references, and to formulate more sophisticated (and less conservative) principles. $^{29}$ The circumstances characterizing the transitional scenario-the same circumstances that pragmatic genealogy focus on in formulating the dysfunctionality argument-are obviously prominent candidates to this justificatory role. ${ }^{30}$ Granting them such a role, I believe, would align a contextualist approach to the issue of punishment in transitional cases with the approach of scholars, like Murphy, that take transitional justice as a peculiar kind of justice with its own guiding principles, attuned to the specifics of transitional scenarios.

Downstream, at the level of judgments, the argument maintains its relevance in that it still provides a reason against resorting to punishment to the extent that our retributive feelings recommend. In this capacity, however, this argument differs from those arguments straightforwardly stressing the importance of securing stability, reconciliation and the conditions for peaceful coexistence against the demands for punishment that retributive justice (either for the offenders or for the victims) gives rise to. These arguments aim at tilting the scale of reasons by adding more weight to the side of peace. This can be done in a variety of ways and it is a move perfectly within the reach of contextualists as well as of virtually every theorist (see, for

\footnotetext{
29 Previously, I equated the lack of critical distance with the idea of a conservative bias. My claim that pragmatic genealogy can correct this problematic aspect of contextualism may appear puzzling now because the position the genealogical argument supports - a position stressing the importance of peace over justice-seems itself quite conservative. As an anonymous reviewer noticed, in many transitional contexts indigenous and ethnic minorities - as usual victims of a regime's oppression - are often the ones stressing the importance of justice and punishment over peace. This consideration gives me the occasion to clarify the argument. The fact that the position supported here is not one associated with actors typically playing a progressive role in real politics does not, I believe, invalidate my point. The reasons are twofold. First, because these actors do not always play a progressive role in real politics. Some ethnic and indigenous minorities, for one thing, endorse patriarchal social models and are themselves quite conservative. Second, and most importantly, because the notion of conservatism I rely on here is not informed by the contestations of real politics at all. It is purely analytical and denotes the tendency to accept with insufficient scrutiny established conceptions, views and norms. In this sense, the position my argument leads to is not conservative.

30 In Murphy's account, these circumstances are four, namely pervasive structural inequality, normalized and collective political wrongdoing, serious existential uncertainty and fundamental uncertainty about authority (see Murphy 2017, p. 33).
} 
instance, Miller 2013, p. 64). The line of argument I proposed here contributes to the same outcome but in a crucially different way in that it does not add more weight to the side of peace but rather substracts weight from the side of justice. It does so by showing that justice's demands for punishment might be misplaced in the case at hand because satisfying them through and through would defy the very purpose for which human beings have, raise and normally respond to that sort of demands. This, of course, does not mean that this latter line of reasoning is more productive or fruitful than the former. It rather offers a valuable complement to it, supporting the same conclusion with its own resources.

The second aspect worth clarifying about this argument concerns the character of the reason it provides. As reported in its formal version above, this reason is prima facie, in the sense that certain considerations may undermine it and other reasons may outweigh it. ${ }^{31}$ A consideration that would undermine this reason is that the account of punishment on which it rests is either wrong or worse than a competing one. As for contrasting reasons, it takes only a little imaginative effort to rearrange the transitional scenario in a way that gives rise to them. For instance, the people who endured the oppression of those who colluded with the overturned regime may have the possibility of (and reasons for) forming a new, separated state in which to live by themselves. In this case, they might simply disregard the concern for cooperation and peaceful co-existence and thus resort to punishment as extensively as they think appropriate. Or it might be the case that not punishing wrongdoers enough will let resentment mount in the population, thus jeopardizing peace. ${ }^{32}$ These are all valid points I neither want nor need to deny. I do not need to deny them because arriving at a justifiable deliberative output on complex issues such as the role punishment should play in transitional cases will necessarily involve a delicate balancing of reasons pulling in different directions. Having provided a valid and original input, I believe I can rest my case.

\footnotetext{
31 This is a declaredly unprecise characterization of prima facie reasons in that it embodies the defining feature of pro tanto reasons too. I hope that the widespread diffusion of this unprecise characterization, together with the following clarification, makes it excusable. As far as I know, the soundest way of drawing the distinction is the one proposed by Reisner. The term pro tanto, when applied to a reason, implies that the reason is weighty as far as it goes. Reasons of this kind may be supported by more pro tanto reasons pointing in the same direction or counterweighted by others supporting some alternative. They would imply a final, conclusive or overriding reason, say, to $\Psi$, only if there are no other divergent pro tanto reasons or other considerations, like side constraints or prima facie reasons not to $\Psi$, that apply. Prima facie reasons, on the other hand, are in one way stronger and in one way weaker than pro tanto reasons. 'The way in which they are stronger is that the fact that one prima facie ought to do something implies that one finally ought to do it, unless the prima facie ought is undermined. [...] The way in which prima facie oughts are weaker than pro tanto oughts is that the latter retain their force, even if outweighed, whereas the former may be completely inoperative if undermined' (Reisner 2013, p. 3).

${ }^{32}$ I am grateful to an anonymous reviewer for pushing me on this point.
} 


\section{Conclusion}

I started my inquiry from the problem of critical distance (CDP), a deep-seated problem for contextualist approaches and especially for theoretical contextualism, among whose endorsers there are Michael Walzer, David Miller and Andrea Sangiovanni. I then proceeded to investigate possible solutions to this problem, looking for tools that could not only compensate for contextualism's lack of critical distance but also ensure some degree of action-guidance and distinctiveness. Driven by Tully's and others' claims about the critical purchase of genealogical reconstructions, I compared two different approaches to genealogy and tested the most promising one against the transitional case after having shown the shortcomings of Walzer's, Miller's and Sangiovanni's approaches with respect to this case. By doing so, I showed that the Foucaultian conception of genealogy as a problematizing device does not provide any guidance for action, whereas the functionalist approach to genealogy pioneered by Williams not only supplies this guidance but proves to be a particularly effective tool to deal with practices, like punishment, that are impervious to synchronic methods of functional interpretation, like Sangiovanni's one.

If the way in which I conducted the test and the way in which I interpreted the results are correct, pragmatic genealogy represents a good solution to the CDP in that it satisfies the relevant desiderata highlighted above. First, it is consistent with theoretical contextualism's assumptions and it thus satisfies the desideratum of distinctiveness. Second, it satisfies the desideratum of critical distance because it does not simply repeat the dominant conception of, or the existing norms at work in, the target practice. It rather provides a detached and autonomous perspective on the practice and its norms, from which their assumptions can be questioned. Moreover, pragmatic genealogy satisfies the action-guidance desideratum in that it does not simply highlight contradictions and inconsistencies in the practice of punishment, but it provides reasons to either uphold it or reject it. In the transitional case, this guidance found expression in a dysfunctionality argument questioning the normative standing of the practice of punishment.

Joseph Carens once claimed that contextualism incorporates an important Burkean insight, namely 'that our institutions and practices contain forms of wisdom that theories and pure reflection can hardly capture' (2004, p. 122). By claiming so, he probably pointed out a belief that many contextualist political theorists share, implicitly defend or at least indirectly support. Now, Carens might be right. There might be some form of wisdom in the social meanings that we happen to share, in some of the relationships we establish, in certain institutional arrangements and in some of the practices in which these elements are often intertwined. Moreover, it is certainly possible that this wisdom might not be evident from the purely theoretical standpoint of abstract and universal principles. However, we cannot simply assume that such wisdom is there. If we want to stick responsibly to contextualism and compensate for its lack of critical distance, we need a tool to assess whether our practices contain any wisdom and, if they do, to bring this wisdom to light, so that the justificatory role assigned them by contextualists can be questioned and, if warranted, validated. In this paper, I argued that pragmatic genealogy can be such a 
tool, because it can help us see through the mist of historical contingency and discern, in light of the needs they address and the functions they serve, how far certain practices are worthy of our allegiance.

Funding Open access funding provided by Università degli Studi di Milano within the CRUI-CARE Agreement. No specific funding supported this research.

Availability of data and material Not applicable.

\section{Declaration}

Conflict of interest The author declare that he has no competing interests.

Open Access This article is licensed under a Creative Commons Attribution 4.0 International License, which permits use, sharing, adaptation, distribution and reproduction in any medium or format, as long as you give appropriate credit to the original author(s) and the source, provide a link to the Creative Commons licence, and indicate if changes were made. The images or other third party material in this article are included in the article's Creative Commons licence, unless indicated otherwise in a credit line to the material. If material is not included in the article's Creative Commons licence and your intended use is not permitted by statutory regulation or exceeds the permitted use, you will need to obtain permission directly from the copyright holder. To view a copy of this licence, visit http://creativecommons.org/licen ses/by/4.0/.

\section{References}

Alschuler, Albert. 2003. The changing purposes of criminal punishment. A retrospective on the past century and some thoughts about the next. The University of Chicago Law Review 70 (1): 1-22.

Bedau, Hugo A. and Kelly, Erin. 2019. Punishment. The Stanford encyclopedia of philosophy (Winter 2019 Edition), Edward N. Zalta (ed.), https://plato.stanford.edu/archives/win2019/entries/punis hment/.

Brown, Wendy. 2001. Politics out of history. Princeton, NJ: Princeton University Press.

Buckley, Michael. 2012. Justice in context: Assessing contextualism as an approach to justice. Ethics \& Global Politics 5 (2): 71-94.

Byock, Jesse L. 2003. Feuding in Viking-age Iceland's great village. In Conflict in medieval Europe: Changing perspective on society and culture, ed. Warren Brown and Piotr Gorecki, 229-241. Aldershot: Ashgate.

Carens, Joseph. 2000. Culture, citizenship and community: A contextual exploration of justice as evenhandedness. Oxford: Oxford University Press.

Carens, Joseph. 2004. A contextual approach to political theory. Ethical Theory and Moral Practice 7 (2): $117-132$.

Craig, Edward. 1990. Knowledge and the state of nature: An essay in conceptual synthesis. Oxford: Clarendon Press.

Crouch, Margaret. 1993. A 'limited' defense of the genetic fallacy. Metaphilosophy 24 (3): 227-240.

Cushman, Fiery. 2015. Punishment in humans: From intuitions to institutions. Philosophy Compass 10 (2): 117-133.

Eisikovits, Nir (2017) Transitional justice, The Stanford encyclopedia of philosophy (Fall 2017 Edition), Edward N. Zalta (ed.), https://plato.stanford.edu/archives/fall2017/entries/justice-transitional/.

Fletcher, George. 1999. The place of victims in the theory of retribution. Buffalo Criminal Law Review 3 (1): 51-63.

Fletcher, George. 2000. Rethinking criminal law. Oxford: Oxford University Press.

Foucault, Michel. 1977. Discipline and punish: The birth of the prison. Harmondsworth: Penguin. 
Fricker, Miranda. 2007. Epistemic injustice: Power and the ethics of knowing. Oxford: Oxford University Press.

Garland, David. 2001. The culture of control: Crime and social order in contemporary society. Oxford: Oxford University Press.

Geuss, Raymond. 2001. History and illusion in politics. Cambridge: Cambridge University Press.

Hamilton, Lawrence. 2003. The political philosophy of needs. Cambridge: Cambridge University Press.

Haque, Adil A. 2005. Group violence and group vengeance: Toward a retributivist theory of international criminal law. Buffalo Criminal Law Review 9 (1): 273-328.

Hills, Matthew. 2021. Conflicts and reasons in contextual normative theory: A reply to Modood and Thompson. Res Publica 27: 145-150.

Hudson, Barbara. 1987. Justice through punishment. A critique of the justice model. New York: St Martin's Press.

Kaufman, Whitley. 2013. Honor and revenge: A theory of punishment. Dordrecht: Springer.

Kelly, Erin. 2018. The limits of blame. Rethinking punishment and responsibility. Cambridge, MA: Harvard University Press.

Klement, Kevin C. 2002. When is genetic reasoning not fallacious? Argumentation 16 (4): 383-400.

Koopman, Colin. 2013. Genealogy as critique. Foucault and the problems of modernity. Bloomington, IN: Indiana University Press.

Ignatieff, Michael. 1978. A just measure of pain: The penitentiary in the industrial revolution. London: Macmillan.

Lægaard, Sune. 2016. Contextualism in normative political theory. Oxford Research Encyclopedia of Politics. https://doi.org/10.1093/acrefore/9780190228637.013.87.

Lægaard, Sune. 2017. The role of interpretation of existing practice in political argument. Critical Review of International Social and Political Philosophy 22 (1): 87-102.

Lægaard, Sune. 2019. Contextualism in normative political theory and the problem of critical distance. Ethical Theory and Moral Practice 22 (4): 953-970.

Lampe, Ernst Joachim. 1970. Rechtsanthropologie: Eine Strukturanalyse des Menschen im Recht. Berlin: Duncker \& Humblot.

Lampe, Ernst Joachim. 1987. Genetische Rechtstheorie Recht. Evolution und Geschichte. Karl Alber: Freiburg im Breisgau.

Lorenzini, Daniele. 2020. On possibilising genealogy. Inquiry. https://doi.org/10.1080/0020174X.2020. 1712227.

Lorini, Giuseppe, and Michelina Masia, eds. 2020. Antropologia della vendetta. Napoli: ESI.

Maculan, Elena, Gil Gil, and Alicia. . 2020. The rationale and purposes of criminal law in transitional contexts. Oxford Journal of Legal Studies 40 (1): 132-157.

Malarino, Ezequiel. 2012. Judicial activism, punitivism and supranationalisation: Illiberal and antidemocratic tendencies. International Criminal Law Review 665 (12): 665-695.

Malinowski, Bronislaw. 2018 [1926]. Crime and custom in savage society, London: Routledge.

Mascaretti, Giovanni Maria. 2019. Foucault, normativity, and freedom: A reappraisal. Foucault Studies 27 (1): 23-47.

May, Larry. 2012. After war ends: A philosophical perspective. Cambridge: Cambridge University Press.

Melossi, Dario, and Massimo Pavarini. 1981. The prison and the factory: Origins of the penitentiary system. London: Macmillan.

Miller, David. 1995. Complex equality. In Pluralism, justice, and equality, ed. D. Miller and M. Walzer, 197-225. Oxford: Oxford University Press.

Miller, David. 2001. Principles of social justice. Cambridge, MA: Harvard University Press.

Miller, David. 2013. Justice for earthlings. Essays in political philosophy. Cambridge: Cambridge University Press.

Modood, Tariq, and Simon Thompson. 2018. Revisiting contextualism in political theory: Putting principles into context. Res Publica 24: 339-357.

Murphy, Colleen. 2017. The conceptual foundations of transitional justice. Cambridge: Cambridge University Press.

Nietzsche, Friedrich. 2006 [1887]. On the genealogy of morality. Cambridge: Cambridge University Press.

Nisbett, Richard E, and Dov Cohen. 1996. Culture of honor: The psychology of violence in the south. Boulder, CO: Westview Press.

Nozick, Robert. 1974. Anarchy, state and Utopia. New York: Basic Books. 
Owen, David. 2002. Criticism and captivity: On genealogy and critical theory. European Journal of Philosophy 10 (2): 216-230.

Pashaman, Jon. 1970. Is the genetic fallacy a fallacy? Southern Journal of Philosophy 8 (1): 57-62.

Pfiffner, James P. 2010. US blunders in Iraq: De-baathification and disbanding the army. Intelligence and National Security 25 (1): 76-85.

Prinz, Janosch, and Paul Raekstad. 2020. The value of genealogies for political philosophy. Inquiry. https://doi.org/10.1080/0020174X.2020.1762729.

Prittwitz, Cornelius. 1999. The resurrection of the victim in penal theory. Buffalo Criminal Law Review 109 (3): 109-129.

Queloz, Matthieu. 2021. The practical origins of ideas: Genealogy as conceptual reverse-engineering. Oxford: Oxford University Press.

Queloz, Matthieu. 2020a. How genealogies can affect the space of reasons. Synthese 197: 2005-2027.

Queloz, Matthieu. 2020b. From paradigm-based explanation to pragmatic genealogy. Mind 129 (515): 683-714.

Queloz, Matthieu, and Damian Cueni. 2020. Left wittgensteinianism. European Journal of Philosophy. https://doi.org/10.1111/ejop.12603.

Rawls, John. 1996. Political liberalism. Paperback. New York: Columbia University Press.

Reader, Soran. 2007. Needs and moral necessity. London: Routledge.

Reichenbach, Hans. 1961. Experience and prediction: An analysis of the foundations and the structure of knowledge. Chicago: University of Chicago Press.

Reemtsma, Jan. 1999. Das Recht des Opfers auf die Bestrafung des Täters -als Problem, Munich: CH Beck Verlag.

Rossi, Enzo. 2019. Being realistic and demanding the impossible. Constellations 26 (4): 638-652.

Sabia, Dan. 2010. Defending immanent criticism. Political Theory 38 (5): 684-711.

Sanchez, Jesus Maria Silva. 2009. Una critica a las doctrinas penales de la 'lucha contra la impunidad' y del 'derecho de la victima al castigo del autor'. Revista De Estudios De La Justicia (11): 35-56.

Sangiovanni, Andrea. 2008. Justice and the priority of politics to morality. The Journal of Political Philosophy 16 (2): 137-164.

Sangiovanni, Andrea. 2016. How practices matter. The Journal of Political Philosophy 24 (1): 3-23.

Seibert-Fohr, Anja. 2009. Prosecuting serious human rights violations. Oxford: Oxford University Press.

Skinner, Quentin. 1998. Liberty before liberalism. Cambridge: Cambridge University Press.

Smyth, Nicholas. 2017. The function of morality. Philosophical Studies 174 (5): 1127-1144.

Solinas, Marco. 2019. The political deficit of immanent critique. On Jaeggi's objections to Walzer's criticism. Critical Horizons. https://doi.org/10.1080/14409917.2019.1676947.

Southwood, Nicholas. 2011. The moral/conventional distinction. Mind 120 (479): 761-802.

Srinivasan, Amia. 2019. Genealogy, epistemology and worldmaking. Proceedings of the Aristotelian Society CXIX (2): 127-156.

Teitel, Ruti. 2000. Transitional justice. Oxford: Oxford University Press.

Testini, Francesco. 2020. Testing pragmatic genealogy in political theory: The curious case of John Rawls. European Journal of Political Theory. https://doi.org/10.1177/1474885120909777.

Tiisala, Tuomo. 2017. Overcoming 'the present limits of the necessary': Foucault's conception of a critique. The Southern Journal of Philosophy. 55 (1): 7-24.

Tully, James. 2008. Public philosophy in a new key. Volume I: Democracy and Civic Freedom. Cambridge: Cambridge University Press.

Von Hirsch, Andrew. 1976. Doing justice: The choice of punishment (Report of the committee for the study of incarceration). New York: Hill and Wang.

Walzer, Michael. 1983. Spheres of justice. New York: Basic Books.

Walzer, Michael. 1994. Thick and thin. Moral arguments at home and abroad. Notre Dame: Notre Dame University Press.

Weisberg, Michael. 2013. Simulation and similarity: Using models to understand the world. Oxford: Oxford University Press.

Wiggins, David. 2002. Claims of needs. In Needs, values, truth: Essays in the philosophy of values, 3rd edn, 1-58. Oxford: Clarendon Press.

Williams, Bernard. 2002. Truth and truthfulness: An essay in genealogy. Princeton, NJ: Princeton University Press.

Wittgenstein, Ludwig. 1986. Philosophical investigations. Oxford: Basil Blacwell. 
Publisher's Note Springer Nature remains neutral with regard to jurisdictional claims in published maps and institutional affiliations. 